MATEC Web of Conferences 33, 03012 (2015)

DOI: $10.1051 /$ matecconf/ 20153303012

(c) Owned by the authors, published by EDP Sciences, 2015

\title{
Martensitic transformation and shape memory effect in NiTi alloy covered by chitosan/silver layer
}

\author{
Tomasz Goryczka ${ }^{a}$, Anna Kokoszka, Bożena Łosiewicz, Mateusz Dulski \\ University of Silesia, Institute of Materials Science, Silesian Center for Education and Interdisciplinary Research, 75 Pułku Piechoty $1 A$, \\ 41-500 Chorzow, Poland
}

\begin{abstract}
The NiTi shape memory alloy was covered with chitosan/silver layer. Coatings were deposited at room temperature using combination of processing parameters such as deposition voltage and amount of silver in colloidal suspension. Structure of layers was studied by means of X-ray diffraction. Quality of the coatings was evaluated basing on observations done in scanning electron microscopy. Transformation behaviour of coated samples was studied with use of differential scanning calorimeter. The covered sample revealed presence of the reversible martensitic transformation and ability to deformation (in bending mode) up to $8 \%$. Forward martensitic transformation, in as-received NiTi alloy and in alloy after layer deposition occurred in two steps B2-R-B19'. After deformation quality of the chitosan/silver layer remained unchanged.
\end{abstract}

\section{Introduction}

In recent years, effect of the progress done in the field of materials science is widely used in many areas of life. A particularly important use of this science is medicine. Thanks to the possibilities of combining methods as well as surface modification, it is possible to design complex functional materials, resulting in innovative products with specific functions for medical applications.

The NiTi shape memory alloy is one of the most attractive materials for implants as well as a parts of medical devices [1]. This alloy possesses unique property such as shape memory phenomena, which is closely correlated to the reversible thermoelastic martensitic transformation [2]. It reveals good corrosion resistance and biotolerance compared to other alloys applied in medicine. Due to their bioavailability, they are used to produce staples for the treatment of bone fractures, stents, orthodontic arches, clamps for anastomosis, etc. or in the manufacture of minimally invasive surgery tools [3-5]. However, they are used for manufacturing a short-term implant. It means, those whose period of residence in a living organism do not exceed more than two years. Although nickel is in the intermetallic phase, there is a risk associated with the diffusion of alloying element to surface. In consequence, the toxic substances may undergo unwanted reactions with the surrounding tissues and give rise to allergy [6-7].

One of the methods for human body protection from the harmful effects of nickel ions migration is a modification of the surface [8]. Currently, there are many methods applied for NiTi surface modification, which also improve corrosion resistance, reducing bacterial adhesion and a biofilm formation. These include diamond coatings, apatite, biopolymer composite and titanium oxides and nitrides. However, one should take into account the impact of technological conditions for layers/coatings producing on the occurrence of shape memory phenomena and deformations associated with induction of these effects [9-13].

Recently, an attractive method for surface modification of NiTi alloys has been electrophoretic deposition, which offers the possibility of producing thin films and coatings made from biopolymer, inorganic, metallic and/or composite materials. It deserves special attention because the process of the coating preparation can be carried out at temperatures, which do not affect the structure and phase composition of NiTi alloy [14-15].

Application of biopolymer as covers make possible to build-in a various kind of particle as well as drugs for the controlled release process. In this case, the biodegradable polymers, which could include chitosan as well as the metal particles (silver, gold, cooper ect.) can be used. Especial attantion is drown by chitosan for its properties as a biodegradability, bioactivity, antimicrobial activity, non-toxicity, the ability for toxic metals absorption. Moreover, chitosan may play a role of matrix for embedding silver particles. Silver is also known from enhancing the action of the antimicrobial, antiviral and antifungal properties [16-17].

The purpose of presented work was to cover NiTi shape memory alloy with chitosan/silver $(\mathrm{CH} / \mathrm{Ag})$ layer with use of electrophoresis and check its influence on the course of the martensitic transformation as well as shape recovery. Also, quality of coated surface (after shape recovery) was studied.

a tomasz.goryczka@us.edu.pl

This is an Open Access article distributed under the terms of the Creative Commons Attribution License 4.0, which permits unrestricted use distribution, and reproduction in any medium, provided the original work is properly cited. 


\section{Experimental procedure}

The commercial NiTi alloy (Memry GmbH), with chemical composition: $49,4 \mathrm{at} \% \mathrm{Ti}$ and $50,6 \mathrm{at} \% \mathrm{Ni}$, was used as a substrate for the $\mathrm{CH} / \mathrm{Ag}$ layer deposition. From the sheet $(50 \mathrm{~cm} \times 8 \mathrm{~cm} \times 1 \mathrm{~mm})$, several samples were cut off. They were in a rectangular shape with dimensions of $10 \mathrm{~mm} \times 8 \mathrm{~mm}$ and $1 \mathrm{~mm}$. Surface, before layer deposition, was polished with polishing papers as well as a silica suspension with gradation down to $0,1 \mu \mathrm{m}$.

The chitosan/silver $(\mathrm{CH} / \mathrm{Ag})$ layers were deposited in one process on the NiTi substrate by cataphoresis. Colloidal suspension of deposited substrates was prepare from $1 \%(\mathrm{v} / \mathrm{v})$ aqueous citric acid solution, in which $1 \mathrm{~g} / \mathrm{dm}^{3}$ of chitosan powder had been dissolved at room temperature. Amount of the silver powder in suspension varied from $0,2 \mathrm{~g} / \mathrm{l}$ up to $4 \mathrm{~g} / \mathrm{l}$. The layers were electrophoretically deposited at a voltage varied from $5 \mathrm{~V}$ to $20 \mathrm{~V}$ at a constant deposition time of $120 \mathrm{~s}$.

Structure of the deposited layer was studied with use of X'Pert Pro diffractometer applying cooper radiation $\left(\mathrm{Cu}_{\mathrm{Kacl}}\right.$ and 2$)$. Sequence of the reversible martensitic transformation was checked using structural studies basing on X-ray diffraction pattern measured by Empyrean diffractometer equipped with cooling/heating attachment. This studies were carried out with cobalt radiation $\left(\mathrm{Co}_{\mathrm{Kac1}}\right.$ and 2$)$.

Surface of the deposited samples were observed with use of scanning electron microscope JEOL JSM 6480.

Differential scanning calorimeter (DSC) Mettler Toledo DSC-1 was applied for studies of the thermal behaviour. Thermograms were measured with cooling/heating rate of $10 \mathrm{deg} / \mathrm{min}$.

\section{Results and discussion}

\subsection{Materials before layer deposition}

The as received NiTi alloy was used as a substrate for $\mathrm{CH} / \mathrm{Ag}$ layer deposition. In order to check its phase composition the diffraction pattern was measured at room temperature (Fig. 1). Diffraction lines were identified as belonging to the B2 parent phase (PDF-4 card no. 74051). There was no evidence of other equilibrium phases such as $\mathrm{Ni}_{2} \mathrm{Ti}$ or $\mathrm{Ti}_{2} \mathrm{Ni}$.

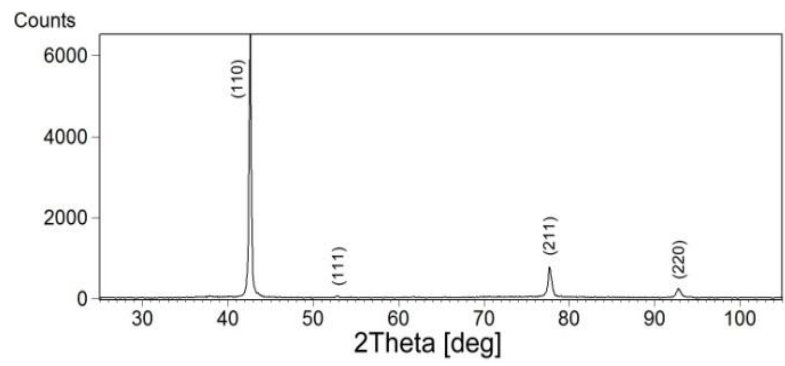

Figure 1. X-ray diffraction pattern measured for the as-received NiTi alloy.
Measured thermograms revealed, that martensitic transformation proceeds in two-step during cooling (Fig. $2)$. First step refers to the $\mathrm{B} 2 \rightarrow \mathrm{R}$-phase transition, whereas second to the R-phase $\rightarrow \mathrm{B} 19^{\prime}$. It is worthy to notice that in the thermal region of the martensite formation, transformation occurred in two-stages. Mechanism of that phenomena can be found at [18-20]. The as-received sample reveals, that reversible martenistic transformation occurred in thermal range between $-95,8^{0} \mathrm{C}\left(\mathrm{M}_{\mathrm{f}}\right)$ and $10,5^{\circ} \mathrm{C}\left(\mathrm{A}_{\mathrm{f}}\right)$.

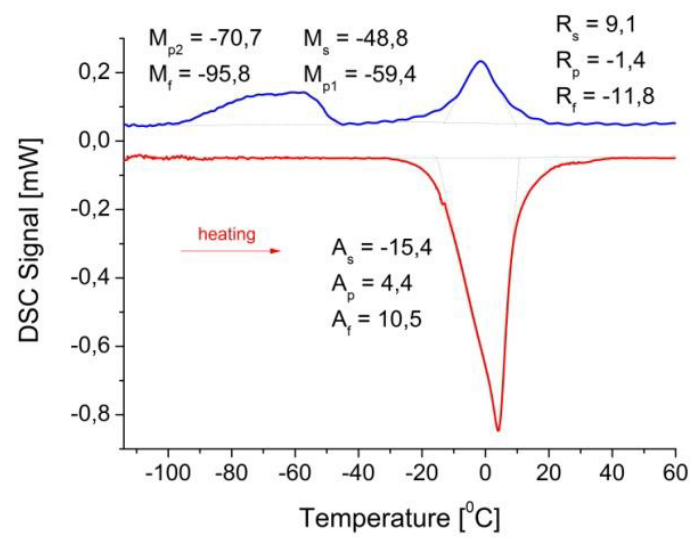

Figure 2. Thermograms measured for the NiTi alloy before layer deposition.

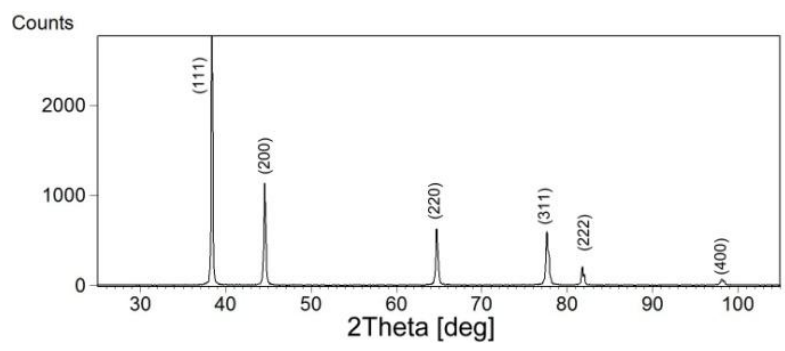

Figure 3. X-ray diffraction pattern measured for the commercial Ag before its deposition.

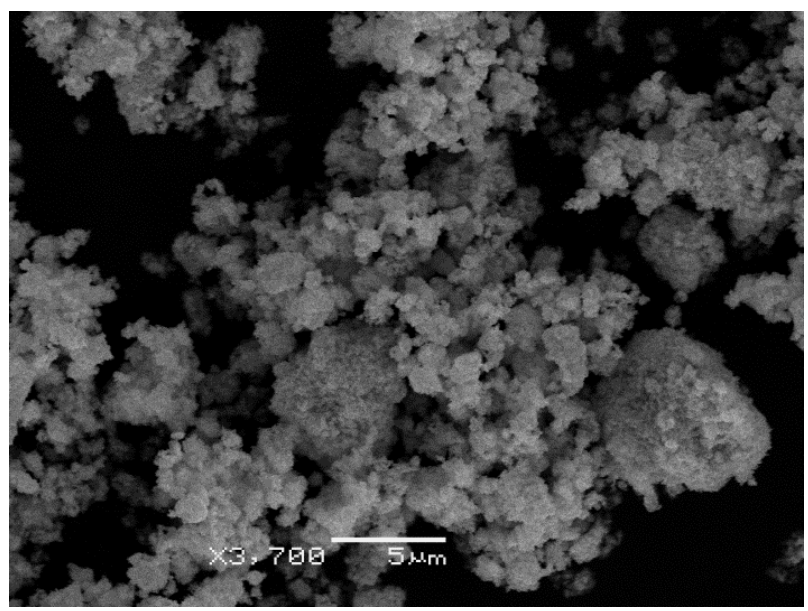

Figure 4. SEM image observed for the commercial Ag before its deposition. 
In order to produce the composite layer commercial silver (Alfa Aesar) was used with a purity of $99.9 \%$. Measured X-ray diffraction pattern showed, that the Ag is a polycrystalline (Fig. 3). Phase identification was done basing on the PDF-4 card no. 1-1167. According to the manufacturer's specifications size of the silver particles was 1 to 5 microns. However, observation done in scanning electron microscope (SEM) revealed, that particle were also consolidated into agglomerates having a diameter of several micrometers (Fig. 4).

The commercial chitosan powder (Sigma Aldrich) having a deacetylation degree of 75-85 \% and a medium molecular weight of 190-310 kDa was used for layer deposition (Fig. 5). X-ray diffraction phase analysis showed, that the chitosan is in a semi-crystalline state (Fig. 6). The PDF-4 card no 40-1518 confirmed phase identification. Broadening of the diffraction lines comes from the nature of polymer structure. Relatively high density of diffraction lines in combination with their overlapping may give the impression that chitosan is amorphous, which was not true.

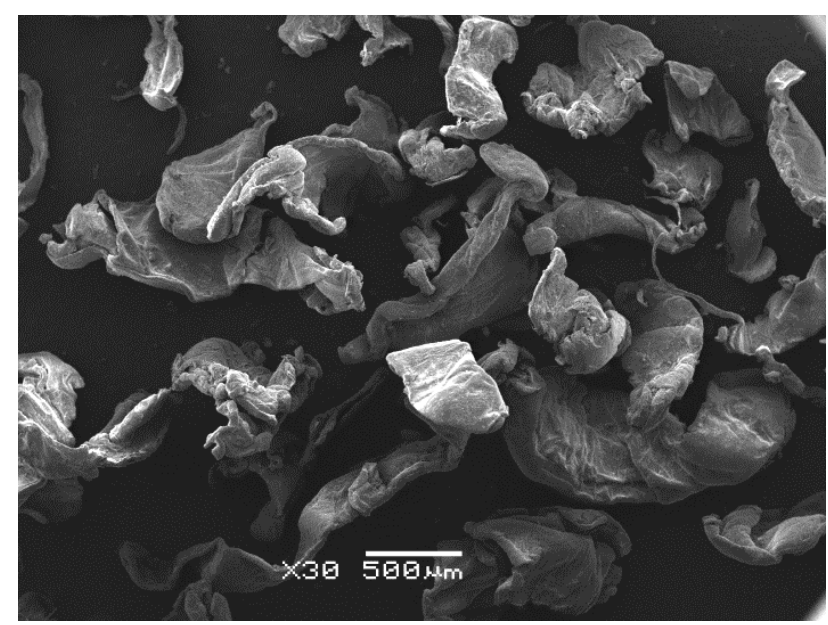

Figure 5. SEM image observed for the chitosan used for layer deposition.

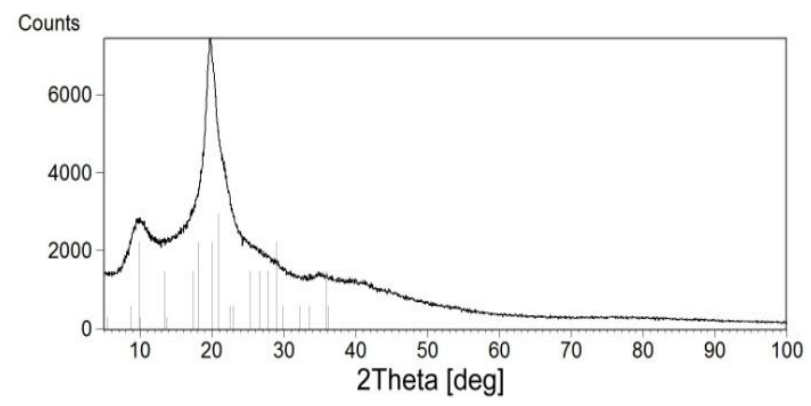

Figure 6. X-ray diffraction patterns measured for chitosan before deposition.

\subsection{NiTi alloy after $\mathrm{CH} / \mathrm{Ag}$ deposition}

The quality of the coatings was evaluated on the basis of the observations made at the scanning electron microscopy. Examples of the observed SEM images are shown in Fig 7.
In general, the coatings were continuous, without cracks or breaks and strictly adhered to the substrate over its surface. Apart from the fact, that colloidal suspension for layer deposition was carefully mixed for several hours, silver was deposited in the form of agglomerates as well as single-particles. Silver particles were embedded in a matrix of chitosan, but also extend above the surface of the coating.

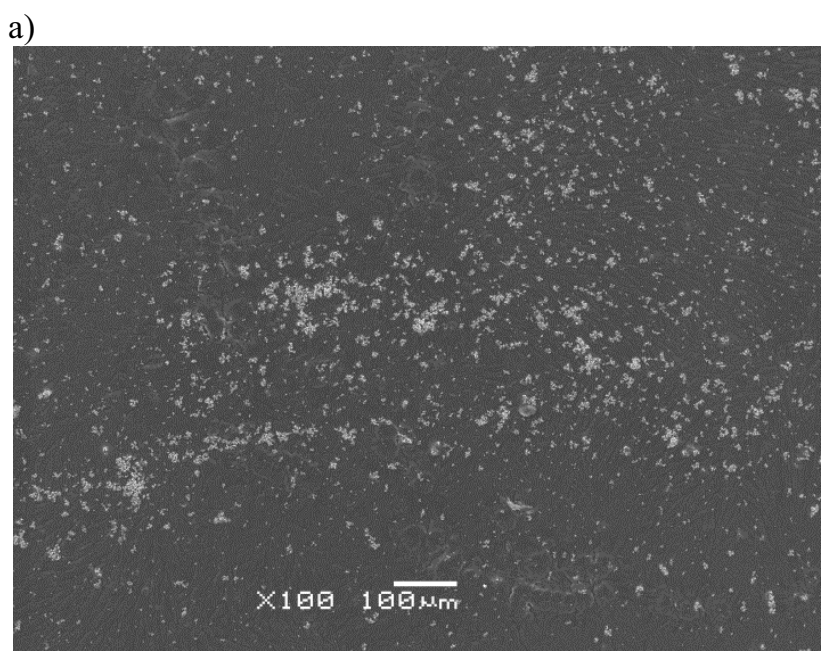

b)

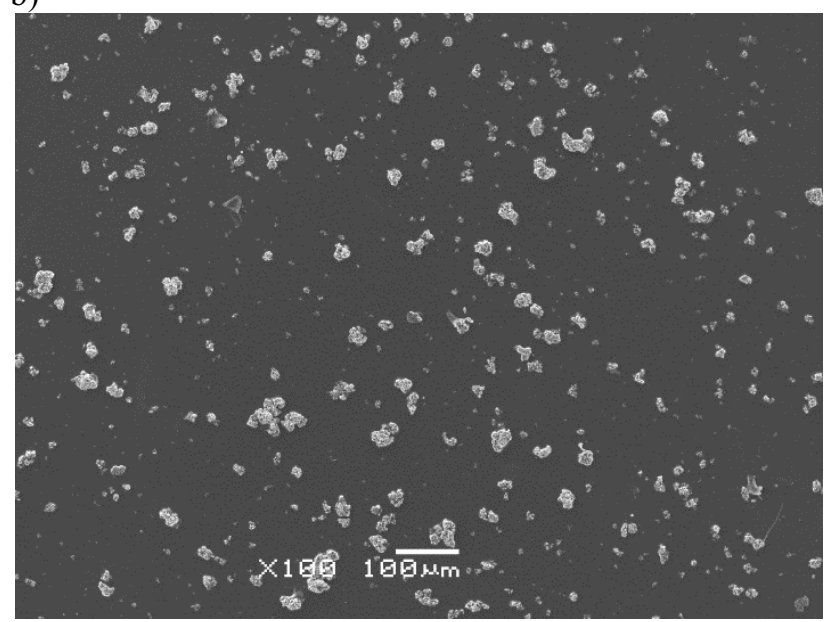

c)

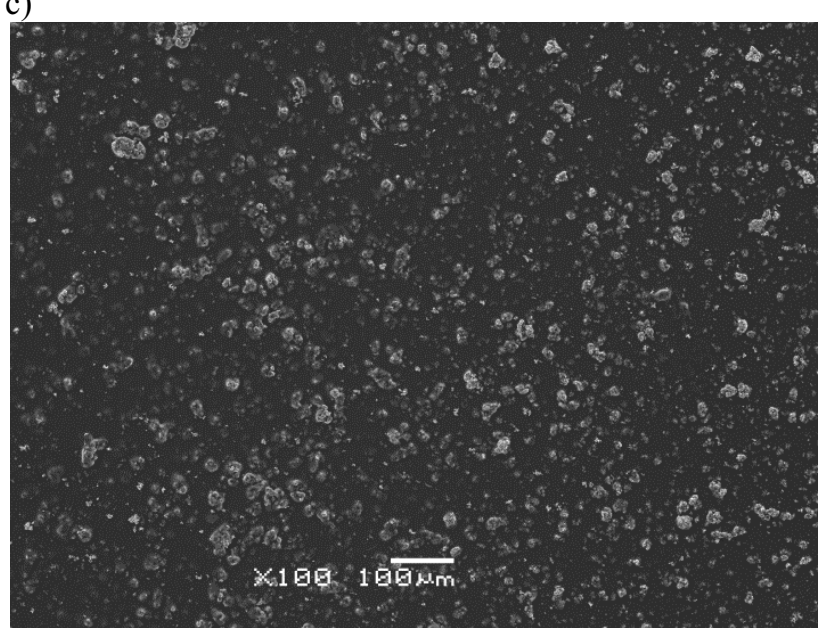

Figure 7. SEM images of $\mathrm{CH} / \mathrm{Ag}$ coatings deposited on $\mathrm{NiTi}$ surface at $5 \mathrm{~V}$ (a); $10 \mathrm{~V}$ (b) or $20 \mathrm{~V}$ (c). 
The size of deposited agglomerates varied from about $1 \mu \mathrm{m}$ up to tens of micrones. The use of lower deposition voltage caused deposition of finer particles and smaller agglomerates.

However, increasing of deposition voltage led to settle larger agglomerates. Also, density of deposited particles/agglomerates per $\mathrm{mm}^{2}$ increased together with increase of deposition voltage. On the other hand, the samples deposited at lower voltage revealed a higher amount of silver in not-embedded areas.

In order to confirm a presence of the $\mathrm{CH} / \mathrm{Ag}$ coating deposited on surface of the NiTi alloy, the X-ray diffraction patterns were measured using an X-ray grazing incidence diffraction technique (GIXD). The patterns were registered at constant angle of incidence beam $(\alpha)$ at 0,$2 ; 0,3 ; 0,5 ; 1 ; 2,5$ and 5 degrees. In this technique, the penetration depth of the beam decreases with decreasing of angle of incidence beam. In consequence, X-ray diffraction pattern measured at lower angle brings information about phase composition from the layer, which is at the top of the surface.

Figure 8a shows X-ray diffraction patterns measured, at constant $\alpha$-angle of $1^{0}$ (green line) and $0,5^{0}$ (red line) for pure chitosan deposited on the NiTi alloy. The X-ray diffraction pattern measured at $1^{0}$ shows presence of two broaden maxima and two diffraction lines. Both diffraction lines come from the B2 parent phase. However, two broaden peak (Maximum 1 and Maximum 2) come from scattering effect of the X-ray beam on amorphous chitosan. Their value of the half-width at maximum intensity (FWHM) reaches almost 10 degrees. In comparison to the chitosan before its deposition, the FWHM of the strongest diffraction line (maximum at $20^{0}$ ) does not exceed $0,8^{0}$. It is evidence that after electrophoretic deposition chitosan was in an amorphous state. Similar effect was observed for chitosan deposited together with silver in $\mathrm{CH} / \mathrm{Ag}$ coatings.

a)

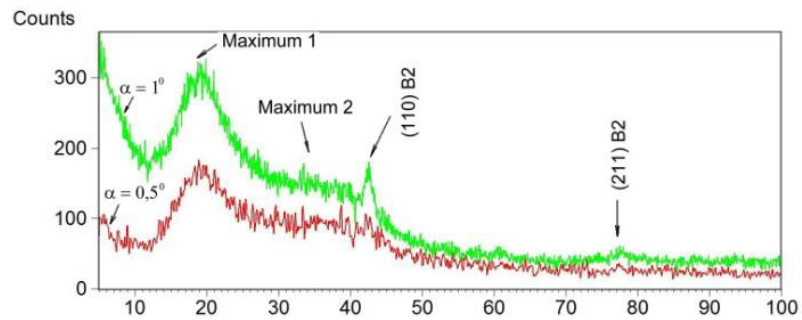

b)

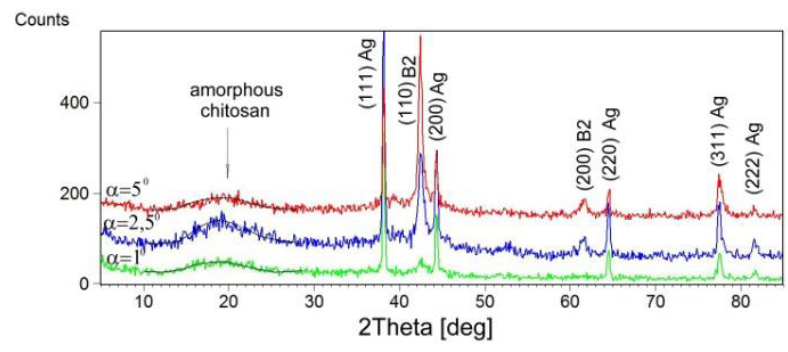

Figure 8. X-ray diffraction patterns measured for chitosan (a) and $\mathrm{CH} / \mathrm{Ag}(\mathrm{b})$ deposited on the NiTi alloys at 20V/120s.
Regardless applied deposition parameters, structural effect of $\mathrm{CH} / \mathrm{Ag}$ coatings deposited on the surface of the NiTi alloys, was similar. Example is shown in Fig. 8 b. The X-ray diffraction patterns measured at various $\alpha$ angles proved that coatings consisted of amorphous chitosan in combination with the crystalline silver.

\subsection{Martensitic transformation in coated alloy}

The course of the martenistic transformation was studied by means of the X-ray diffraction versus temperature change. X-ray diffraction patterns were measured every 3 degrees in thermal range between $50^{\circ} \mathrm{C}$ and $-119^{\circ} \mathrm{C}$ during cooling as well as heating. From measurement density of intensity of diffraction line was calculated and plotted in relation between temperature change and position of diffraction lines (Fig. 9). The maximum of diffraction line intensity was marked in red-brown colour, whereas minimum in blue. An example of received results, for forward martensitic transformation, occurred in alloy covered with $\mathrm{CH} / \mathrm{Ag}(20 \mathrm{~V} / 120 \mathrm{~s})$, is shown in Fig. 9a. In order to keep figure readable, only diffraction lines from $2 \theta$ range between 44-56 degrees were shown.

a)

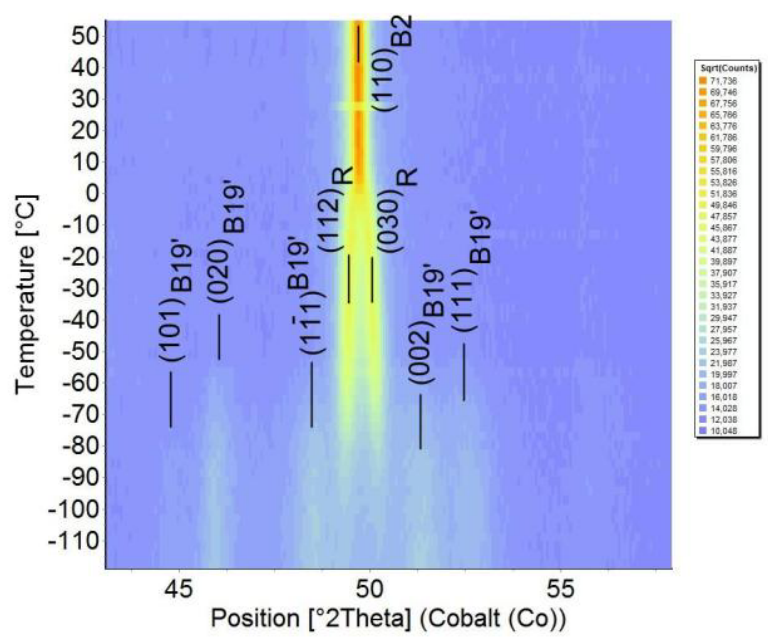

b)

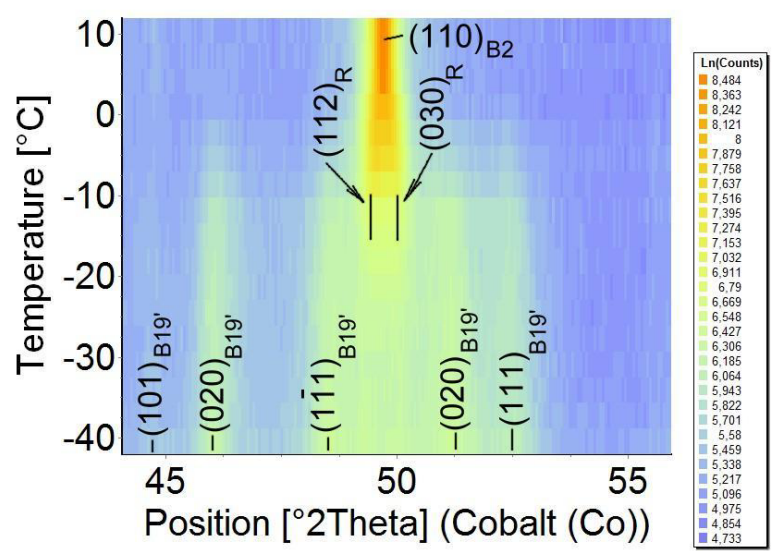

Figure 9. Intensity of X-ray diffraction line versus temperature change calculated from measurement done for the NiTi alloy with $\mathrm{CH} / \mathrm{Ag}$ coating deposited at $20 \mathrm{~V} / 120$ s during cooling (a) and heating (b). 
It can be clearly seen that above room temperature the strongest (110) diffraction line of the B2 phase was present. During further cooling, it splits into two lines of the R-phase: $(112)_{\mathrm{R}}$ and $(030)_{\mathrm{R}}$. Additional cooling down to $-50^{\circ} \mathrm{C}$ causes vanishing of both lines and simultaneously, rising of diffraction lines, which belong to the monoclinic B19' martensite. The diffraction lines $(112)_{R}$ and $(030)_{R}$ with vanishing intensity are present even the temperature lowered to about $-90^{\circ} \mathrm{C}$. It can be evidence, that in some region the R-phase still exists. Detailed observations made on scanning electron microscope revealed the existence of the $\mathrm{Ti}_{2} \mathrm{Ni}$ precipitates. Measurements of the chemical composition, done near precipitates, pointed to the deviation from the nominal one. This fact may have contributed to the occurrence of the R-phase in these areas. Such mechanism was reported at [19]. In comparison to the DSC measurements (example for as-received NiTi alloy was shown in Fig. 2), the $\mathrm{B} 2 \rightarrow \mathrm{R}$ transformation should be completed at about $-12^{0} \mathrm{C}$. However, deviation of the DSC cooling curve from the course of the base line suggests that this transformation finished at lower temperature.

During heating, reversible martensitic transformation occured (Fig. 9b). In general, the B19' martensite transforms to the B2 parent phase. However, at low temperatures a track of intensities derived from $(112)_{\mathrm{R}}$ and $(030)_{\mathrm{R}}$ can be clearly distinguished. Prove for that behaviour can be also seen at DSC heating curve. The thermal peak at heating curve was asymmetrical. Its asymmetry was very weak and practically not distinguishable. Thus, the $\mathrm{A}_{\mathrm{s}}$ temperature was adopted as the start temperature of the reversible transformation.

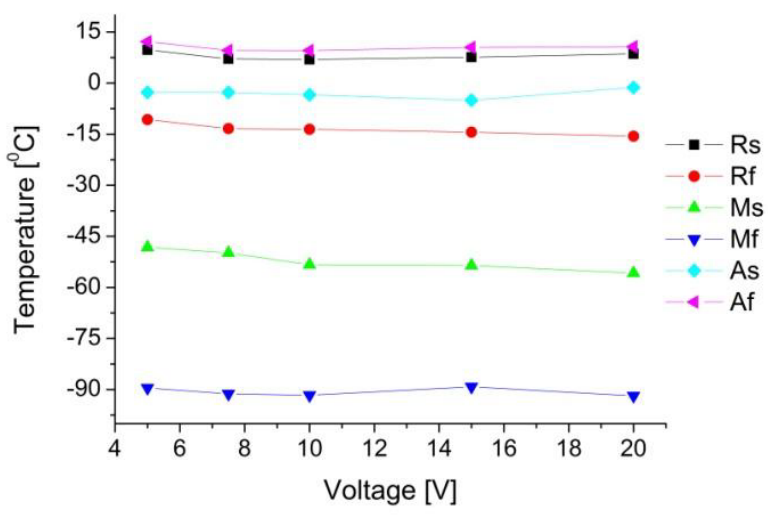

Figure 10. The characteristic transformation temperatures of the martenistic transformation versus applied voltage for electrophoretic deposition.

In order to analyse influence of the electrophoretic deposition process of $\mathrm{CH} / \mathrm{Ag}$ coatings on the course of the martensitic transformation, the characteristic transformation temperatures were calculated from measured DSC cooling/heating curves. Results are shown in Fig. 10. In general, increase of the deposition voltage caused decrease of the transformation temperatures. However, the differences between samples deposited at 5 $\mathrm{V}$, in reference to the $20 \mathrm{~V}$, are lower than $5^{\circ} \mathrm{C}$.
In summary, similar thermal behavior of the martensitic transformation was stated for all NiTi samples covered with various electrophoretic conditions. Regardless deposition parameters, transformation proceeds into two clearly separed steps on cooling, whereas on heating they overlapped. It can also be concluded, that conditions of eletrophoretic deposition as well as chemical composition of the $\mathrm{CH} / \mathrm{Ag}$ coatings does not influence the course of the martenistic transformation as well as its characteristic temperatures.

\subsection{Shape memory effect in coated alloy}

Quality of the deposited coatings as well as a shape memory effect was studied after sample bending resulted in its loading/unloading cycles. Two cycles were done. First, coated samples were deformed approximately up to $3 \%$ and unload. Then, they were loaded almost up to $8 \%$ and again unload. All coated samples recovered their straight shape. No evidence of a plastic deformation was stated. The surface of coatings was observed at scanning microscope after each cycle in a bended position. An example of the experiment, done for the NiTi alloy covered by $\mathrm{CH} / \mathrm{Ag}$ at $20 \mathrm{~V} / 120$ s, is shown in Fig. 11.

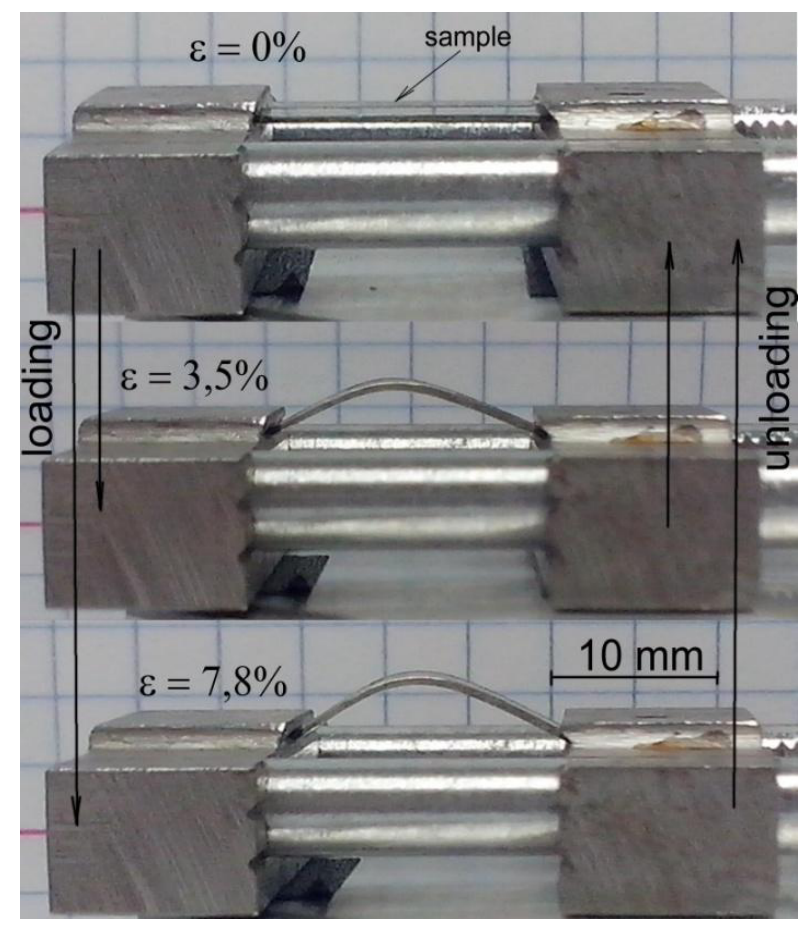

Figure 11. Steps in shape recovering done in the bending test carried out for the NiTi alloy covered by $\mathrm{CH} / \mathrm{Ag}$ coatings at $20 \mathrm{~V} / 120$ s.

Observation done in SEM revealed, that after sample bending up to $8 \%$ surface was smooth and continuous without any cracks or breaks (Fig. 12). It is an evidence, that polymer is elastic and followed deformation done in the NiTi matrix. Moreover, silver particles as well as agglomerates were still embedded in the chitosan. 


\section{Conclusions}

Obtained results can be conluded as follows:

- The electrophoretic technique has proved to be an effective technique to produce, in one single deposition process, composite coatings chitosan/silver on the surface of NiTi alloy.

- The increase of deposition voltage causes an increase of silver amount as well as their size, built into the chitosan matrix.

- The conditions applied to the production of coatings chitosan/silver do not cause structural changes in the alloy NiTi maintaining the character and the reversibility of the martensitic transformation.

- Covered NiTi alloy with chitosan/silver layer reveals shape recovery, in bending mode, up to $8 \%$. After shape recovery deposited layers were continuous and without any cracks or damaged.

a)

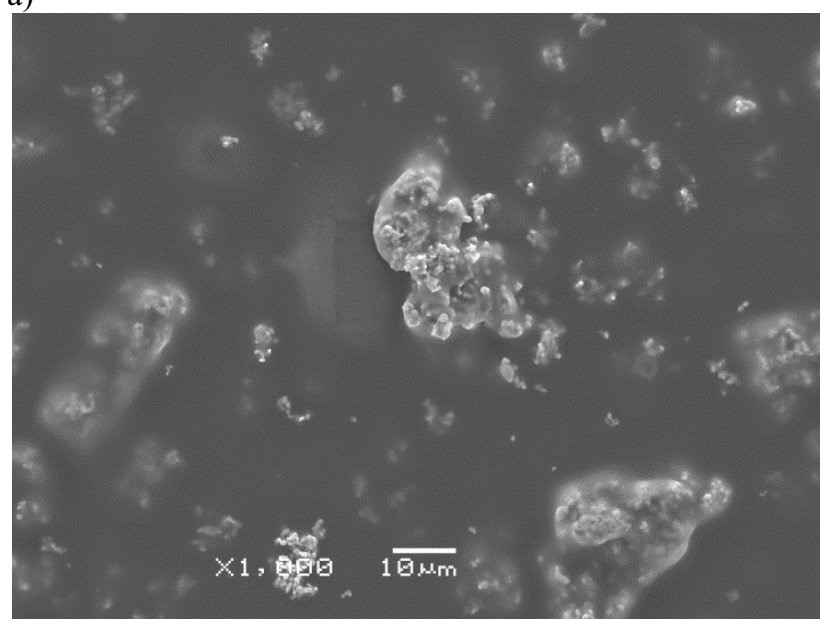

b)

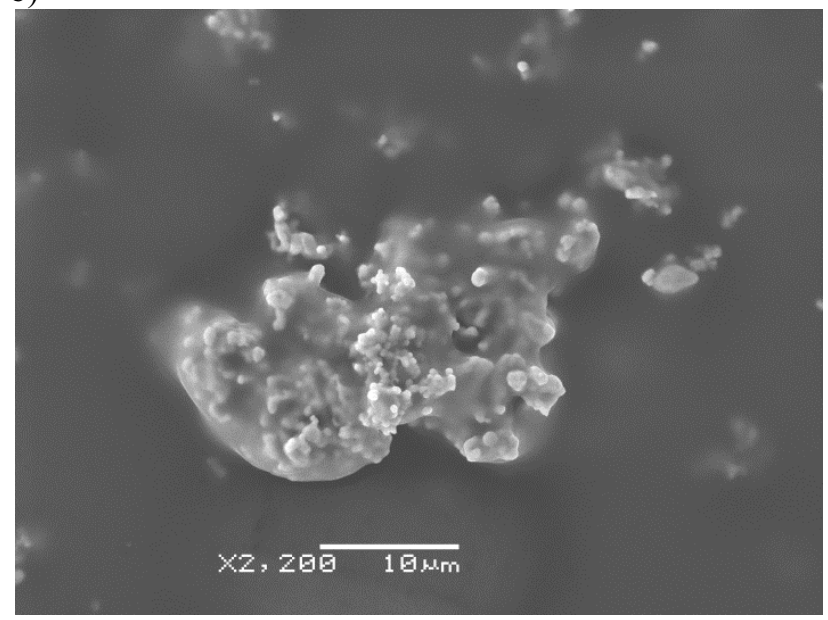

Figure 12. SEM images observed for the NiTi alloy covered by $\mathrm{CH} / \mathrm{Ag}(20 \mathrm{~V} / 120 \mathrm{~s})$ after bending up to $8 \%$.

\section{References}

1. A.R. Pelton, D. Stockel, T.W. Duerig, Mater. Sci. Forum. 327-328, 363 (2000)

2. K. Otsuka, C.M. Wayman, Mechanism of Shape Memory Effect and Superelasticity, Shape Memory Materials, (Cambridge University Press, Cambridge, 1998)

3. R.C. Robinson, P.J. O’Neal, G.H. Robinson, J. Oral Maxillofac. Surg. 59, 539 (2001)

4. F.R. Carls, H.F. Sailer, J. Craniomaxillofac. Surg. 26, 197 (1998)

5. N.B. Morgan, Mat. Sci. Eng., 378, 16 (2004)

6. K. Ozeki, T. Yuhta, H. Aoki, Y. Fukui, Bio-med. Mater Eng., 13, 271 (2003)

7. H. Huang, Y. Chiu, T. Lee, S. Wu, H. Yang, K. Su, Ch. Hsu, Biomat. 24, 3585 (2003)

8. F. Sun, K.N. Sask, J.L. Brash, I. Zhitomirsky, Colloids and Surfaces B: Biointerfaces 67, 132 (2008)

9. S. Shablovskaya, J. Ryhanen, R L. Yahia, Mat. Sci. Forum 394-395, 131 (2002)

10. H. Morawiec, J. Lelatko, G. Stergioudis, T. Goryczka, A. Winiarski, P. Paczkowski, Eng. of Biomaterials 37, 32 (2004)

11. G.S. Firstov, R.G. Vitchev, H. Kumar, B. Blanpain, J. Van Humbeeck, Biomaterials 23, 4863 (2002)

12. D. Starosvetsky, I. Gotman, Surf. Coat. Technol. 148, 268 (2001)

13. M.G. Fyta, C. Mathioudakis, G. Kopidakis, P.C. Kelires, Thin Solid Films 473, 56 (2005)

14. P. Kowalski, B. Łosiewicz, T. Goryczka, Arch. Metall Mater. 60, 171 (2015)

15. P. Kowalski, B. Łosiewicz, T. Goryczka, Solid State Phen. 203, 236 (2013)

16. A. Ewald, S.K. Glückermann, R. Thull, U. Gbureck, BioMedical Engi, OnLine 5, 22 (2006)

17. N.M. Alves, J.F. Mano, Int. J. Biol. Macromol. 43, 401 (2008)

18. H. Morawiec, D. Stroz, T. Goryczka, D. Chrobak, Scripta Mater. 35, 485 (1996)

19. J. Khalil-Allafi, G. Eggeler,A. Dlouhy,W.W. Schmahl, Ch. Somsen, Mater.Sci. Eng. A 378, 148 (2004)

20. D. Chrobak, D. Stroz, H. Morawiec, Scripta Mater. 48, 571 (2003) 